\title{
PEER INSTRUCTION. A TOOL TO INVOLVE STUDENTS ON THE LEARNING PROCESS
}

\author{
Pablo Díaz-García, Eva Bou-Belda, Ignacio Montava Seguí, Jaime Gisbert-Payá, \\ Marilés Bonet-Aracil
}

Universitat Politècnica de València, Departamento de Ingeniería textil y Papelera (SPAIN)

\begin{abstract}
Teaching at engineering schools is affected, as many other disciplines, by the necessity of moving from traditional lecturing to more active methods. Preparation to real work must not be only focused on the special skills related to the studies but include transversal competences as well. Those competences must be focused on what society is supposed to request. Peer Instruction (PI) is a didactic method that began in 1990 by Professor Eric Mazur to teach Physics. It is based on explaining briefly a concept and let the student to develop it firstly individually and later on in groups. $\mathrm{PI}$ is a teaching strategy in which two-three students discuss and explain their thinking in relation to a specific topic. The objective of the discussion is a deeper understanding of the topic or problem under discussion, which makes them much more likely to remember and use the concept and ultimately produce more quality learning. The act of explaining and defending what one has understood against the alternative explanations of others, helps students to become deeply involved in learning.

The aim of this paper is to show the results of an experience when Peer instructions was adapted and used in a different subject from physics. The method was used among the students in an optional subject at Engineering studies in design, a subject from textile engineering area. Three important concepts on the subject were selected. The contents were thought by flip teaching as a recorded lesson (less than 10 minutes). The student answered a test and worked in teams in the classroom discussing which was the correct answer. Finally, the team answered and it was analyzed, offering feedback to the whole class. It was evidenced that students changes their attitude towards considering different points of view and tackling the subject from different points of view. The results from the experience also showed how the method was capable to move the students to work in teams and the benefits of it. Students also gave importance to the feedback given at the end of each topic, they considered it necessary despite getting a good mark as it allowed them to get a deep knowledge.
\end{abstract}

Keywords: engineering, active methodology, cooperative, self-thinking.

\section{INTRODUCTION}

Teaching at engineering schools is affected, as many other disciplines, by the necessity of moving from traditional lecturing to more active methods. Engineering studies are requested to prepare the student to the professional activity. This profession can be widely diverse such as the industrial engineering and the civil engineering. Despite they both are engineering, they both request special skills and some of them are common. The future engineer must be conveniently prepared on the common topics related with engineering and of course on the special ones related with its specialty. However, this preparation to real work must not be only focused on the special skills related to the studies but include transversal competences as well. Those competences must be focused on what society is supposed to request. Nowadays, considering we are living in a competitive environment, those competences are basically, critical thinking, problem solving, creativity, lifelong learners [1,2].

Of course, the student we have nowadays must be considered, and improving learning process begins by understanding the youth. At present, the student is considerably different from our generation of students. We have not always the same kind of student, now we are not dealing with millennials, at this moment we have the classrooms with people called $Z$ generation. They are considered digital natives but are also characterized by being impatient and the lack of trust on the educational system, they also are characterized by being self-learners [3].

Some studies have been focused on the proven effective teaching methods even for engineering, some of them are [4]:

- Formulate and publish clear instructional objectives 
- Establish relevance of curse material and teach inductively

- Balance concrete and abstract information in every course

- Promote active learning in classroom

- Use cooperative learning

- Give challenging but fair tests

- Convey a sense of concern about students' learning.

In order to have the student involved on the learning process, they must appropriate the objectives. The student must perceive the objectives as their own.

Students need to be aware of where each subject leads and the degree as a whole to perceive the meaning and relevance of their effort. This is the essential condition to assume their studies as their own challenge, get involved in it and conduct their work autonomously and self-regulated [5].

The choice of strategies that promote active and collaborative participation in the learning process has a measurable effect on student performance and its commitment to the subject, which in Anglo-Saxon terminology is known as engagement [6-8]. Zywno, M. S. [9] showed that the adoption of complementary or optional activities can be directly related to student satisfaction and their level of involvement in engineering studies. The majority of student engagement is measured in terms of quantitative data such as attendance, standardized tests scores and truancy or graduation rates [2].

The most traditional practice of asking questions during classes only involves highly motivated students, a more structured questioning process such as the one that follows in peer instruction (peer Instruction PI) gets every student in the class involved. PI is a didactic method that began in 1990 by Professor Eric Mazur [10], dean of the Area of Applied Physics at Harvard University. This method has been tested for years and its effectiveness has also been investigated [11-17]. The construction of different standards in the class when applying PI has also been investigated [18]. This method is applied in the classroom, students get involved in their own learning, focusing their attention on the underlying concepts. Classes consist of short presentations of key topics followed by a proof of concept. These conceptual tests are called conceptual tests (CT).

$\mathrm{PI}$ is a teaching strategy in which two-three students discuss and explain their thinking in relation to a specific topic. The objective of the discussion is a deeper understanding of the topic or problem under discussion, which makes them much more likely to remember and use the concept and ultimately produce more quality learning. The act of explaining and defending what one has understood against the alternative explanations of others, helps students to become deeply involved in learning.

\section{METHODOLOGY}

\subsection{Participants}

The present study was focused on the Bachelor in Industrial Design and Product Development at Universitat Politècnica de València Campus d'Alcoi. Concisely, the text was conducted among the 13 students from an optional subject in the $3^{\text {rd }}$ course at textile engineering intensification. Participants were $30.77 \%$ male and $60.23 \%$ female, all of them had started they degree more than 3 years ago, none of them had previous experience on the textile engineering field and $23 \%$ were studying and working at the same time.

Due to the reduced number of students who were in one group there was no possibility to obtain a control group from the same class.

\subsection{Procedure}

In order to develop the Peer Instruction method it was necessary to create the CT. Eric Marthur has created them for specific topics while teaching physics concepts. In this case the subject was based on textile materials and the previously designed were not suitable. To begin with this method 3 specific concepts from the syllabus were selected: fiber length, tenacity and pilling. The CT were designed so that the student had to demonstrate a deep understanding of this part by selecting the suitable application of a material depending on the technical characteristics given. 
Previous to the classroom session the student was given some links (maximum 3) with videos of the teacher explaining briefly (no longer than 10 minutes) the basic concept to develop. In order to ensure the student had studied it before attending the classroom an online test was performed. On the face to face session the student had to work in teams of 3 except one of 4 persons. They had 50 minutes to discuss the same questions answered on the online test and reach an agreement about the correct answer. Then, a new answer was offered by the group. The score was $20 \%$ individual mark $+80 \%$ group mark. Later on, a feedback on the correct answer was offered to the student and discussion was opened to make the student understand, if so, their mistake.

In order to determine if the method was capable to improve the engagement of the student towards the subject, and modify their attitude towards the study, a test developed by the Universidad del País Vasco (UPV-EHU) was conducted, before the student started the subject, considering their general attitude to face the study of a subject. Once the 3 topics selected and the method was applied among the students, the same test was conducted but from the way the student faced the study of the current subject.

This questionnaire was divided into different groups of questions and we analyzed only the ones related with the way the student feces the subject or the teacher methodology skipping the ones focused on social matters or issues not concerning the subject. The questions asked to the students will be displayed on the results section so as to avoid repetition.

At the end of the session, and once the marks were definitively uploaded on the system, a focus group of 5 students, randomly selected was interviewed in order to know their personal opinion.

\subsection{Instruments}

This methodology can be considered PI with the inclusion of Flip Teaching as the student was supposed to observe the theory at home and work at the university with the teacher in class. To implement this methodology it was necessary to have access to an online platform were the conceptual lessons were uploaded. Moreover, a special platform to give access to the student to an online test in a defined period, is also necessary.

\section{RESULTS}

The first result we could observe was that the first test was answered by 11 students $(83,33 \%)$ but the rest of the sessions $100 \%$ of the students fulfilled it on time. This was not only because of the engagement of the students on the subject but because there was a recrimination from the rest of the colleagues in the group.

The first group of questions was focused on the way a student faces the subject. Table 1 shows the results and how the student changes their opinion once the PI method was implemented.

Table 1. Behaviour against facing a subject/topic.

\begin{tabular}{|c|c|c|c|c|c|c|c|c|}
\hline \multirow{2}{*}{ How much did you insisted on ...? } & \multicolumn{2}{|c|}{ NEVER } & \multicolumn{2}{|c|}{ SOMETIMES } & \multicolumn{2}{|c|}{ FREQUENTLY } & \multicolumn{2}{|c|}{ ALWAYS } \\
\hline & Before & After & Before & After & Before & After & Before & After \\
\hline Apply theory to problems & 0 & 0 & 4 & 1 & 9 & 2 & 0 & 10 \\
\hline Deep analysis on a topic & 1 & 0 & 6 & 0 & 6 & 3 & 0 & 10 \\
\hline Study a different point of view & 0 & 0 & 8 & 0 & 3 & 2 & 2 & 11 \\
\hline Change your mind from different information & 0 & 0 & 3 & 0 & 7 & 1 & 3 & 12 \\
\hline Memorize a topic & 0 & 13 & 0 & 0 & 5 & 0 & 8 & 0 \\
\hline
\end{tabular}

The analysis of the answers reveals a change in the attitude of the student. When the student has to solve problems before knowing PI method 4 students out of 13 applied sometimes theory to problems and 9 usually, however during the PI method every student considered the theory to solve problems. Moreover, every participant has a positive attitude and faces the study or development with a deep analysis even considering a different point of view and is capable to change their mind if the conclusions demonstrate the first statement was erroneous. 
Table 2 shows the results about how easy is for the student to change their mind or stablish relationships between concepts.

Table 2. Behaviour against stablishing relationships.

\begin{tabular}{|c|c|c|c|c|c|c|c|c|}
\hline \multirow{2}{*}{ How frequently have you ...? } & \multicolumn{2}{|c|}{ NEVER } & \multicolumn{4}{|c|}{ SOMETIMES FREQUENTLY } & \multicolumn{2}{|c|}{ ALWAYS } \\
\hline & Befor & After & Before & After & Before & After & Before & After \\
\hline Combined ideas to solve your tasks & 0 & 0 & 3 & 0 & 8 & 3 & 2 & 10 \\
\hline $\begin{array}{l}\text { Stablished relationships between what you have learnt } \\
\text { and social problems }\end{array}$ & 0 & 0 & 6 & 0 & 5 & 11 & 2 & 2 \\
\hline Analyzed SWOT from your point of view & 0 & 0 & 6 & 0 & 7 & 4 & 0 & 9 \\
\hline Tried to understand your colleagues point of view & 0 & 0 & 3 & 0 & 7 & 0 & 3 & 13 \\
\hline Learn a concept that made you change your mind & 0 & 0 & 3 & 0 & 6 & 6 & 4 & 7 \\
\hline Stablish relationships with other subjects & 0 & 0 & 4 & 0 & 7 & 5 & 2 & 8 \\
\hline
\end{tabular}

Table 2 evidences a shift in the student attitude, as it can be clearly observed once the student has worked with PI method the students are willing to stablish relationships with other subjects or solve problems and consider the SWOT whereas previously the majority did not even considered this approach to solve problems.

Regarding the concept of working in teams, figure 1 shows the student answer to questions related to this topic. As it could be expected, it can be easily appreciated a tendency to increase the work in group affinity once the PI method was applied.

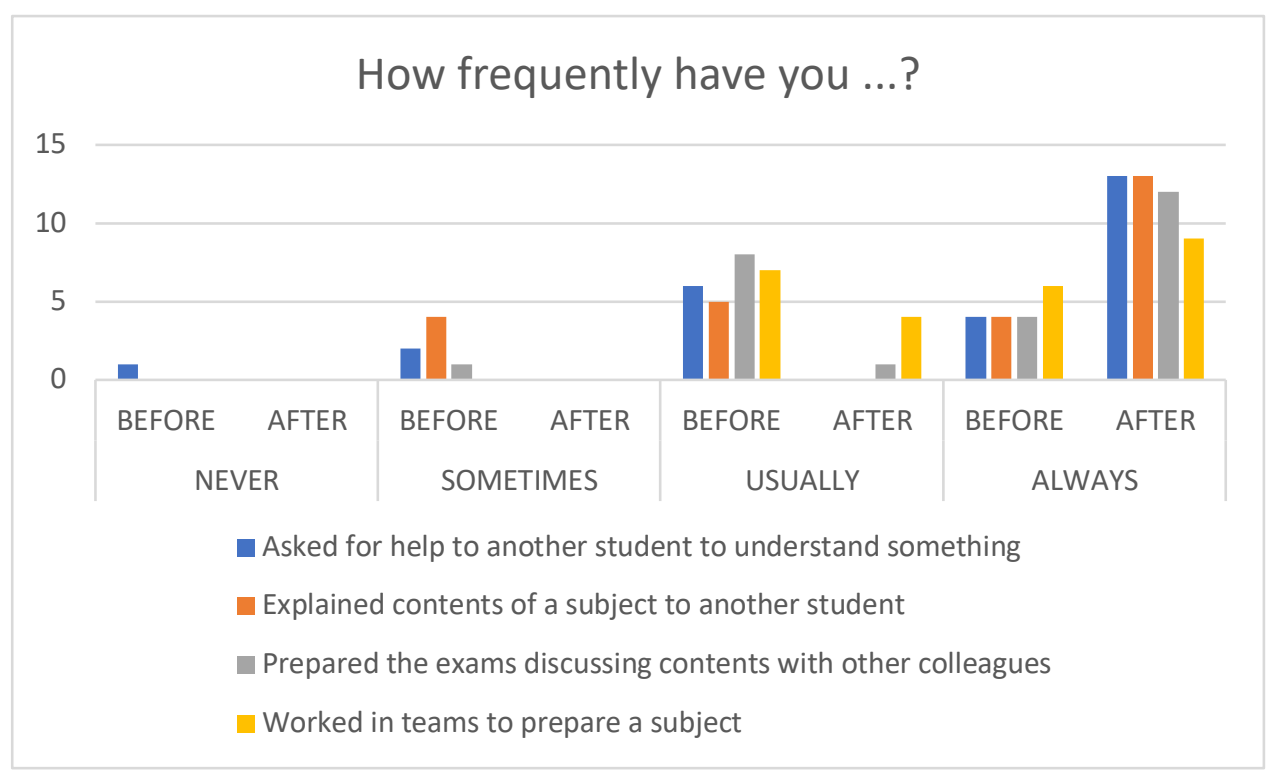

Figure 1. Analysis of the behaviour of the student about working in teams.

Figure 1 evidences a change on the attitude of a student towards working in a team. Once the subject has been studied (after) the majority of the students answered always and a minority usually for every question. This methodology improves the way the student cooperate with their colleagues, and they find the cooperation useful to prepare exams and tests to pass a subject.

Figure 2 shows the results when the teacher action is evaluated. From a general point of view it is easily recognizable that before the PI method was used, less than $84 \%$ of the students never considered the professor was correctly organized. Once the PI method was applied the student has the impression the lessons have been well prepared and the teacher devoted some time to the subject. 


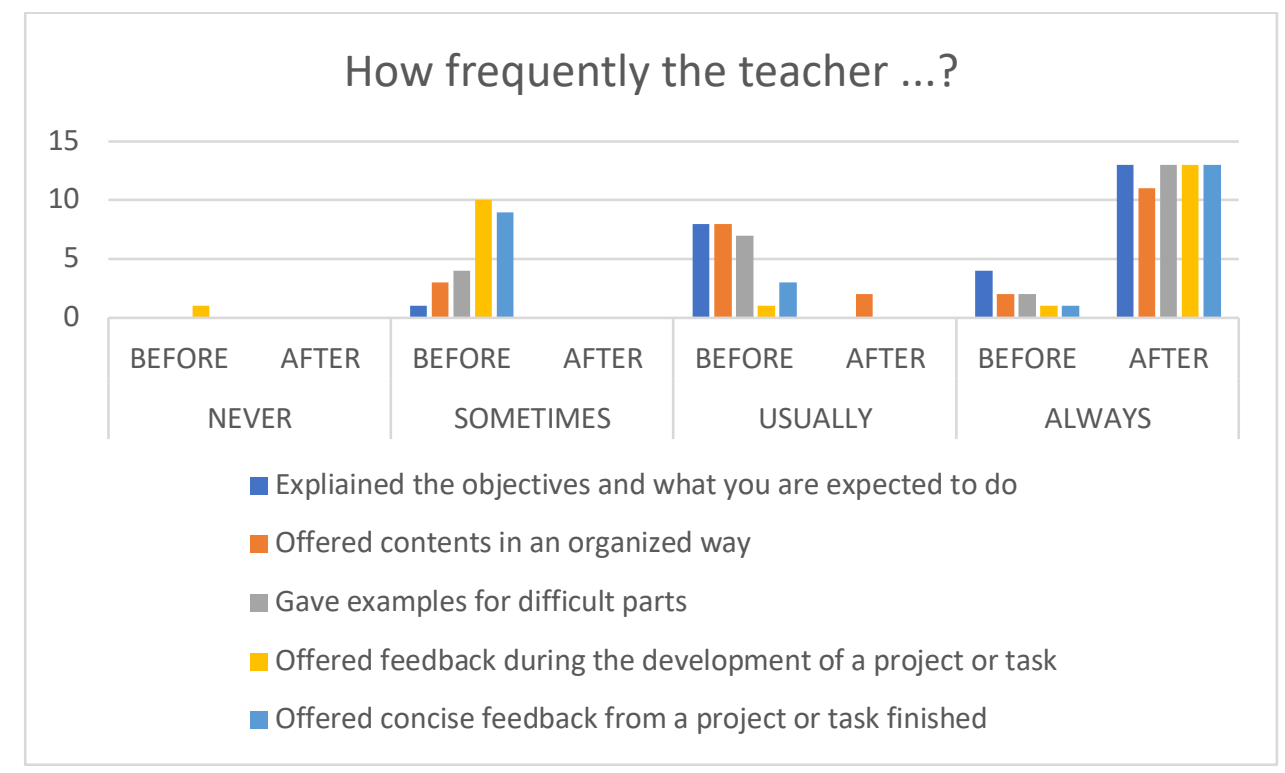

Figure 2. Analysis of the student impression against the teacher organisation.

If we deepen on this section we can observe that despite the fact that many professors show the subject objectives, the sense of knowing which are the subject objectives has increased afterwards and it also deals with giving an impression of order and well organised sessions. Furthermore, the student has the impression that many examples were given to the difficult topics although they were not explained mainly by the teacher and they were introduced by the students during the discussion sessions. Moreover, the vast majority consider that feedback has been offered not only once the task was finished but also during the development of it.

Finally, 5 students were face to face interviewed and they all agreed with the following items:

It is important to consider the relevance of the CT design. All of them agreed that how the problem is questioned is considerably important. Questions must be concise but awake some doubts. It enriches the debate during the class session.

They all gave enormous importance to discussions during class sessions. They were the basis of the success on the students engagement on the subject. Discussion or explaining the concepts to the colleagues is useful to revise your own knowledge and the discussion enriches your confidence on having a deep learning on the subject. This discussion made them feel important as they considered themselves reasserted on the subject.

Although they all knew the existence of the analysis by SWOT during this subject they found it really useful to reach agreements in the team.

One of the aspects that the group found most relevant was the importance of the feedback once the task was finished and corrected. This feedback allowed to know why their answer was correct or incorrect and finally the CT was not merely a mark.

To conclude they wanted to reflect their impression, which was that every student enjoyed studying the concepts by PI method and they all made the objectives a challenge to solve by themselves and found it easy to carry on.

\section{CONCLUSIONS}

It has been proved that $\mathrm{PI}$ is a methodology that encourages students to apply theory to solve problems and study deeply the problems even considering to change the mind if necessary whilst it was not a common attitude before the study of the subject. Furthermore, the student has understood SWOT as a new strategy to solve problems.

Regarding the work in teams, the students have discovered it usefulness and how it can help to strengthen the knowledge about a topic. Moreover, the student is convinced the professor has a deep preparation for the lessons taught by PI method. 
The students impression was the importance the PI method gives to work in teams and how it reassert the knowledge at individual level in every student, considering PI as a suitable method to obtain a deep learning on a topic.

\section{ACKNOWLEDGEMENTS}

Authors would like to acknowledge its participation to students from the $3^{\text {rd }}$ course in Bachelor degree in Industrial Design and Product Development enrolled in the subject Textile Materials at Universitat Politècnica de València during the course 2018/2019.

\section{REFERENCES}

[1] K. Kazerounian, S. Foley, "Barriers to creativity in engineering education: A study of instructors and students perceptions", Journal of Mechanical Design, vol. 129, no. 7, pp. 761-768, 2007.

[2] J. Parsons, L. Taylor, "Improving student engagement". Current issues in education, vol. 14, no. 1, 2011.

[3] M. Dimock, "Defining generations: Where Millennials end and Generation $Z$ begins". Pew Research Center, vol. 17, 2019.

[4] R. M. Felder, D. R Woods, J. E. Stice, A. Rugarcia, "The future of engineering education II. Teaching methods that work". Chemical Engineering Education, vol. 34, no. 1, pp. 26-39, (2000).

[5] N. Entwistle, Teaching for understanding at university: Deep approaches and distinctive ways of thinking. Palgrave Macmillan, 2009.

[6] C. M. Zhao, G.D. Kuh, "Adding value: Learning communities and student engagement," Research in higher education, vol. 45, no. 2, pp. 115-138, 2004.

[7] T. Laird, F. Nelson; G.D. Kuh, "Student experiences with information technology and their relationship to other aspects of student engagement". Research in Higher education, vol. 46, no. 2, pp. 211-233, 2005.

[8] E. R. Kahu, "Framing student engagement in higher education". Studies in higher education, vol. 38, no.5, pp. 758-773, 2013.

[9] M. S. Zywno, Stewart, M. F. "Learning Styles of Students in Technology-Focused vs. Humanities Programs-Gender and Program Differences". In Proceedings of the 2007 International Conference on Engineering Education, Coimbra, PT: ASEE. 2007.

[10] E. Mazur, Peer Instruction: A User's Manual. Prentice Hall Series in Educational Innovation. Pearsons, Saddle River, 1997

[11] C. H. Crouch, E. Mazur, "Peer Instruction: Ten years of experience and results." American Journal of Physics, vol. 69, no. 9, pp. 970-977, 2001.

[12] G. E. Kennedy, Q. I. Cutts, "The association between students' use of an electronic voting system and their learning outcomes". Journal of Computer Assisted Learning, vol. 21, pp. 260-268, 2005.

[13] A. P. Fagen, C. H. Crouch, E. Mazur, "Peer instruction: results from a range of classrooms", The Physics Teacher, vol. 40, pp. 206-209, 2002.

[14] R. R. Hake, "Interactive engagement vs. traditional methods: A six-thousand-student survey of mechanics test data for introductory physics courses" Am. J. Phys., Vol. 66, pp. 64-74, 1998.

[15] D. E. Meltzer, K. Manivannan, "Transforming the lecture-hall environment: The fully interactive physics lecture". American Journal of Physics, vol. 70, no. 6, pp. 639-654, 2002.

[16] M. D. Sharma, J. Khachan, B. Chan, J. O'Byrne, "An investigation of the effectiveness of electronic classroom communication systems in large lecture classes". Australasian Journal of Educational Technology, vol. 21, no.2, pp. 137-154, 2005.

[17] J. A. Shapiro, "Electronic student response found feasible in large science lecture hall", Journal of College Science Teaching, vol. 26, pp. 408-412, 1997. 
[18] C. Turpen, N.D. Finkelstein, "The construction of different classroom norms during Peer Instruction: Students perceive differences". Physical Review Special Topics-Physics Education Research, vol. 6, no 2, pp. 020123, 2010. 